\title{
Optimal distributed generation location and sizing for loss minimization and voltage profile optimization using ant colony algorithm
}

\author{
Adeseye Amos Ogunsina ${ }^{1} \cdot$ Moses Omolayo Petinrin ${ }^{1} \cdot$ Olutomilayo Olayemi Petinrin $^{2,3} \cdot$ Emeka Nelson Offornedo $^{1}$. \\ Joseph Olawole Petinrin ${ }^{4}$. Gideon Olusola Asaolu ${ }^{5}$
}

Received: 18 July 2020 / Accepted: 15 January 2021 / Published online: 1 February 2021

(C) The Author(s) 2021 OPEN

\begin{abstract}
A system of power generation whereby the generating equipment is located close to the point of usage, thereby reducing losses and operation cost is called distributed generation (DG). However, it is imperative that DGs are sited such that the quality of power delivered is optimized and the total real power loss within the system minimized. This paper proposes an approach for optimum sizing and siting of DGs sizing in a power distribution system using Ant Colony Optimization (ACO) algorithm. To validate the algorithm the IEEE 30 bus standard test system was employed. A 92\% decrease in real power loss within the system relative to the value before the connection of DGs was observed, while the minimum bus voltage increased from 0.656 per unit to 0.965 per unit. The results obtained from ACO are further verified by creating an ETAP model of the IEEE 30 bus system and simulating the impact of DG on the system. A significant reduction in total real power losses within the system and improvement in voltage profile was observed when the DGs are placed at the ACO derived sites relative to at other locations. Therefore, Ant Colony Algorithm can be used in deriving the optimum sites and sizes of DGs in a power distribution system.
\end{abstract}

Keywords Ant colony optimization (ACO) · Distributed generation (DG) $\cdot$ Renewable energy $\cdot$ Power flow $\cdot$ Voltage quality

\section{Introduction}

Distributed Generators (DGs) are power generation systems whose output are not connected to a central grid structure for transmission over long distances to the point of usage, rather they are located at the point of usage, with limited or no requirement for transportation [1, 2]. Due to their modularity and portability and little or no requirement for the transportation of the energy resources (fuel) from point of production to the point of usage, renewable energy technologies such as solar photovoltaic and solar thermal systems which harnesses solar energy from the sun and transform it into a suitable form of energy such as heat and electricity are prime candidates for distributed energy generation [3]. Other forms of renewable energy technologies applied in distributed generation systems are small hydro power systems, wind turbines, biogas and biothermal systems and so on. Also, due to the harmful effect of fossil fuel usage on the environment such as the greenhouse effect and global warming, there has been a significant increase in the usage of renewable energy technologies.

$\triangle$ Moses Omolayo Petinrin, mo.petinrin@ui.edu.ng; layopet01@yahoo.com | ${ }^{1}$ Department of Mechanical Engineering, University of Ibadan, Ibadan, Nigeria. ${ }^{2}$ Department of Computer Science, City University of Hong Kong, Kowloon, Hong Kong. ${ }^{3}$ Department of Mathematical Sciences, Kings University, Ode-Omu, Osun State, Nigeria. ${ }^{4}$ Department of Electrical and Electronic Engineering, Federal Polytechnic Ede, Ede, Nigeria. ${ }^{5}$ Power Equipment and Electrical Machinery Development Institute, Okene, Kogi State, Nigeria. 
Thus, due to the variable nature of solar and other renewable energy resources, as their penetration rate into the grid increases, they pose some technical challenges on the system such as feeder overloading, harmonic pollution and so on. Also, high capital cost, low reliability and low efficiency limits the widespread usage of these technologies [1]. Besides, voltage flickers and power fluctuations due to variations in solar irradiation are some of the adverse effects of high penetrated PV in power systems [4]. In their research, Miller and Ye [5] evaluated the impact of using DG as a significant portion of the total energy resources by creating a model of Jeju Island, Korea and made use of three distributed generation systems to assess the potential negative power quality effects of high penetration of DG. Also, Ajan and Nirmala [6] modelled a stand-alone and grid-tied PV system using Simulink which was used to evaluate the relationship between PV system parameters and the output. The various Voltages, Current and Power levels are recorded. The various advantages of optimally allocated DGs in a distribution network such as improvement in overall system voltage, reduction in total system power loss, improvement in system power quality and frequency regulation are highlighted in $[7,8]$.

However, to derive maximum benefits from DG, the generators must be appropriately sized and located within the power distribution network $[7,9,10]$. To achieve this objective, various researchers have proposed different approaches. These methods are classified based on the driving algorithms into metaheuristic, analytical or numerical based methods. Analytical techniques for solving the DG allocation problem are presented in [11-13]. Several authors have also published research studies on optimal allocation of DG and reactive power sources such as capacitors in a distribution system using numerical based techniques [14]. One of such study carried out by Fawzi et al. [15] made use of Dynamic programming. Resener et al. [16] applied Mixed-integer linear programing (MILP). However, these analytical and numerical based methods are often computationally intensive as all possible combinations of DG sites are required to be evaluated to derive the optimum solution. This often limits the number of variables considered in most researches applying these methods. Also, due to the non-linear nature of the problem, the linear programming methods often perform poorly in finding the optimal solutions [17].

Metaheuristic population-based algorithms such as genetic algorithm, firefly, grey wolf, bee colony, particle swarm and ant colony algorithms have an advantage over the numerical and analytical based methods because it doesn't have to cover the entire possible search space in deriving the optimal solution. This helps to minimize the computational resources required and allows for consideration of a large number of variables and buses. Other advantages of these type of algorithms in solving optimization problems include their simplicity and flexibility. They however only derive a near-optimal solution rather than an exact one which is often within acceptable limits for most problems [18]. A metaheuristic cost-benefit approach for the siting and sizing of DGs to ensure the peak demand forecast is optimally met was presented by El-khattam et al. [19]. Kuri et al. [20] applied genetic algorithm for optimal positioning and sizing of DGs in a distribution network, they took into consideration the number of planning years in setting the optimization objectives and constraints. Golshan and Arefifar [21] used an algorithm based on Tabu Search (TS) in solving a comprehensive planning objective for determining the size, locations and mode of operation of Reactive Power Sources (RPSs) and Distributed Generation Resources (DGRs) in a power system. Gandomkar et al. [22], presented a hybrid of simulated annealing and genetic algorithm for solving the problem of DG siting in power distribution networks. Kalkhambkar et al. [23-25] had also implemented the grey wolf algorithm to minimize energy loss in energy storage and renewable distributed generations. Celli et al. [26] proposed a tool to plan and operate DGs for deferment of upgrades in transmission and distribution systems and so on. In the proposed algorithm, multi-objective programming and genetic algorithm (GA) were utilized in a finding the optimum location and number of distributed energy resources to be placed in a network. Similarly, a method for reduction in real power loss, improvement in voltage profile and release of substation in a power system based on analysis of voltage sensitivity index was presented by Gopiya et al. [27].

In simplifying the problem of DG location and sizing, most researchers in the literatures often either fix the number of DGs or the sizes. The proposed method in this paper eliminates this restriction by allowing the algorithm to heuristically search through the entire search space without restricting the possible number of DGs or the capacity of the DGs in deriving the optimum combination of the number, the site and size of DGs to minimize the real and reactive power loss in the system. Due to the relative novelty of ant colony optimization (ACO) algorithm compared to other population-based optimization algorithm and also because ACO was initially designed for discrete problems, not many researches on the suitability of ACO for DG allocation problem has been done. However, ACO has been chosen over other metaheuristic based approach for solving the DG allocation problem for its ability to derive the global optimum solution with minimal number of iterations and its better comparison with other similar algorithms $[28,29]$. This study helps to further explore the application of the ACO algorithm in discrete and continuous problem domain. The ACO algorithm will be applied to 
optimally site and size DGs in a power distribution system such that the total real power loss within the system is minimized while the system voltage profile is significantly enhanced. In order to demonstrate the suitability of the proposed algorithm, it was applied on the IEEE 30-Bus Distribution System.

The remainder of the paper is organized as follows: Sect. 2 provides the mathematical formulation of the problem of real power loss and voltage profile deviation of a power distribution system. The proposed Ant Colony Optimization algorithm for solving the DG optimization problem is presented in Sect. 3, 4. Section 5 presents the model of the case study power distribution system. Analysis and simulation results are presented in Sect. 6. Finally, the conclusion is drawn in Sect. 7.

\section{Problem formulation}

The total real power loss within the distribution system and the deviation of the bus voltages from the nominal voltage magnitude, is given by equations below [30]:

$P_{\text {losses }}=\frac{1}{2} \sum_{i=1}^{N} \sum_{j=1}^{N} \Re\left\{y_{i j}\right\}\left[\left|V_{i}\right|^{2}+\left|V_{j}\right|^{2}-2\left|V_{i}\right|\left|V_{j}\right| \cos \delta_{i j}\right]$

$V_{D}=\sum_{i=1}^{N B}\left(V_{i}-1\right)^{2}$

where $\mathfrak{R}(\bullet)$ denotes the real component of a complex number, $y_{i j}$ is the admittance of the $i j^{\text {th }}$ branch, $N$ is the number of buses, $V_{i}$ and $V_{j}$ denotes the bus voltages, $\delta_{i j}$ is $\delta_{i}-\delta_{j}$.

The objective function to be minimized to derive the best DG allocation for minimum power losses and enhanced voltage profile using ACO is formulated as:

$\min f=P_{\text {Loss }}+w \cdot v_{D}$

The inequality constraints of the minimization algorithm are outlined below:

$$
\begin{aligned}
& \sum_{i=1}^{n D G} P_{D G_{i}}+j Q_{D G_{i}} \leq P_{S / S}+j Q_{S / S} \\
& \max \left\{S_{i j} \text { or } S_{j i}\right\} \leq S_{i j_{\max }} \\
& n D G \leq n D G_{\max } \\
& \left|V_{i}^{\min }\right| \leq\left|V_{i}\right| \leq\left|V_{i}^{\max }\right|
\end{aligned}
$$

$\delta_{i}^{\min } \leq \delta_{i} \leq \delta_{i}^{\max }$

where: $n D G$ is the number of DG sources, $P_{D G_{i}}$ is the real power output of the ith DG source while $Q_{D G_{i}}$ is its reactive power output, $S_{i j}$ is the apparent power flow in the $i j$ th branch and $S_{i j_{\max }}$ is the maximum apparent power flow in the ijth branch.

\section{Optimization algorithm}

In this study, the Ant Colony Optimization (ACO) is proposed for solving the DG allocation problem. ACO is an algorithm that is inspired by the biological behaviour of ants, which enable them to discover the shortest route between their nest and food. Ants do not communicate directly with one another, but they exchange information using what is known as pheromones [31]. When an ant traverses a path in search for food, it lays pheromones on the path, as more ants pass through the shorter path between the nest and the food per unit time relative to the longer path, the quantity of pheromone laid on the shorter path becomes higher than that on the longer path, thereby increasing the probability that an ant will choose the shorter path. The likelihood that an ant will choose a given path, therefore, depends on the quantity of pheromone laid on the path relative to other paths which in turn depends on the number of ants that had previously chosen the same path [28, 32]. The ACO algorithm procedure comprises majorly of three steps: In the first step, the candidate variable values are randomly generated and the pheromone trail is initialized. Secondly, each ant uses the probabilistic state transition rule to find solution to the problem. Thirdly, the pheromone value at each edge is updated, first by evaporating a proportion of the pheromone at all the edges, thereafter the amount of pheromone on paths whose solutions are of high fitness values is reinforced.

\section{Implementation of the algorithm}

The Ant Colony Optimization (ACO) algorithm applied for this study was as presented in [33]. The main steps of the applied ACO algorithm are outlined below:

\subsection{Generation of the candidate variable values}

The solution variables are the real and reactive power generation capacities of the DGs and the bus number at which the generators will be connected. The number of DG is initialized to a certain number. Initially, the candidate variable values for the generators' real and reactive 
power capacity, which are real continuous variables, are randomly sampled subject to the equality and inequality constraints as:

$x_{i}^{(j)}=l_{i}+\frac{u_{i}-l_{i}}{m+\vartheta}\left(j-1+\operatorname{rand}_{i}^{j}\right)$

where $(m+\vartheta)$ is the number of initialized randomly generated solution for variable $\mathrm{i}$, rand ${ }_{i}^{j}$ is a uniformly distributed random number between 0 and $1, i=1,2, \ldots, n$, while $j=1$, $2, \ldots,(m+\vartheta)$. The initial buses for siting the DGs are uniformly randomly chosen from the total number of buses. The randomly generated initial solutions are evaluated and ranked according to their fitness values. The solution with the highest fitness value is captured as the initial global best solution.

Four sources are utilized in generating the variable values from which the ants choose during each iteration, they are: the best solutions derived from all previous iterations, which are also referred to as the global best solution; solutions generated from a random exploration process across the entire solution space; solutions derived from a dynamic exploitation of the solution space around the global best solution; and finally from the values selected by the ants in the last iteration of the algorithm. In each iteration of the ACO algorithm, the m number ants create $\mathrm{m}$ solutions of the problems which serves as candidate values for the next iteration of the algorithm. The best solution from the previous iteration is thereafter compared to the current global best solution in terms of their fitness value, and the global best solution is updated accordingly.

\subsection{Dynamic exploitation process}

This involves the searching of the solution space around $x^{0}=\left(x_{1}^{0}, x_{2}^{0}, \ldots, x_{n}^{0}\right)$, the global best solution, in the interval $\left[x_{i}^{(0)}-r_{i}, x_{i}^{(0)}+r_{i}\right], i=1,2, \ldots, n$. The value of the variables in the global best solution is either increased, decreased or left unchanged according to the following equations:

$\hat{x}_{i}=\left\{\begin{array}{c}\min \left(x_{i}^{(0)}+r_{i} \cdot \sigma_{i}, u_{i}\right), 0 \leq q<1 / 3 \\ x_{i}^{(0)}, 1 / 3 \leq q<2 / 3 \\ \max \left(x_{i}^{(0)}-r_{i} \cdot \sigma_{i}, l_{i}\right), 2 / 3 \leq q<1\end{array}\right.$

where $\sigma_{i} \in(0,1]$ and $q \in[0,1)$ are uniform random values, $i=1,2, \ldots, n$. Then the resulting solution $\hat{x}=\left(\hat{x}_{1}, \hat{x}_{2}, \ldots, \hat{x}_{n}\right)$. If this process generates a solution with a better fitness value than the global best solution, the recorded global best solution is replaced with the derived solution. The process is repeated for $\vartheta$ number of times.

\subsection{Ants' solution construction}

In this step, $m$ ants construct a solution from the generated candidate variable values. An ant $k$ selects a variable with an index $l_{i}^{(k)}$ for the $i$ th variable from the candidate variable values according to (11).

$l_{i}^{(k)}=\left\{\begin{array}{l}\arg \max \left\{\tau_{i}^{(1)}, \tau_{i}^{(2)}, \ldots, \tau_{i}^{(m)}\right\}, \text { if } q<q_{0} \\ L_{i}^{(k)}, \text { otherwise }\end{array}\right.$

where $q$ is a uniform random number based on which an ant either selects a variable with the highest pheromone value among the ones generated in the previous iteration or randomly chooses an index $L_{1}^{(k)} \in\left\{0,1, \ldots, m+g_{i}\right\}$. The probability distribution for the random variable choice is given in (12).

$p_{i}^{(j)}=\frac{\tau_{i}^{(j)}}{\sum_{u=0}^{m+g_{i}} \tau_{i}^{(u)}}, j=0,1, \ldots, m+g_{i}$

The solution derived by each ant from the step above is denoted by $x^{(k)}=\left(x_{1}^{\left(l_{1}^{(k)}\right)}, x_{2}^{\left(l_{2}^{(k)}\right)}, \ldots, x_{n}^{\left(l_{n}^{(k)}\right)}\right)$.

\subsection{Pheromone update}

The solutions generated by all the ants in step 3 are evaluated at the end of each iteration of the algorithm and are sorted in descending order of their fitness value. Thereafter, the amount of pheromones on a predetermined number of variable values are evaporated according to (13).

$\tau_{i}^{(j)} \leftarrow(1-\rho) \cdot \tau_{i}^{(j)}+\rho \cdot T_{\min }$

where $\rho$ is a real number between 0 and 1 which defines the applied rate of pheromone evaporation per iteration of the algorithm, $T_{\min }$ is a predefined constant representing the minimum pheromone value. Also, to ensure convergence of the algorithm towards the global minima, the pheromone values of the best $\psi$ solutions' variable values are reinforced as

$\tau_{i}^{(j)} \leftarrow(1-\alpha) \cdot \tau_{i}^{(j)}+\alpha \cdot T_{\max }$

where $\alpha$ is the defined rate of pheromone reinforcement and it is any number between 0 and 1 . The implementation flowchart for the ACO algorithm is shown in Fig. 1. 


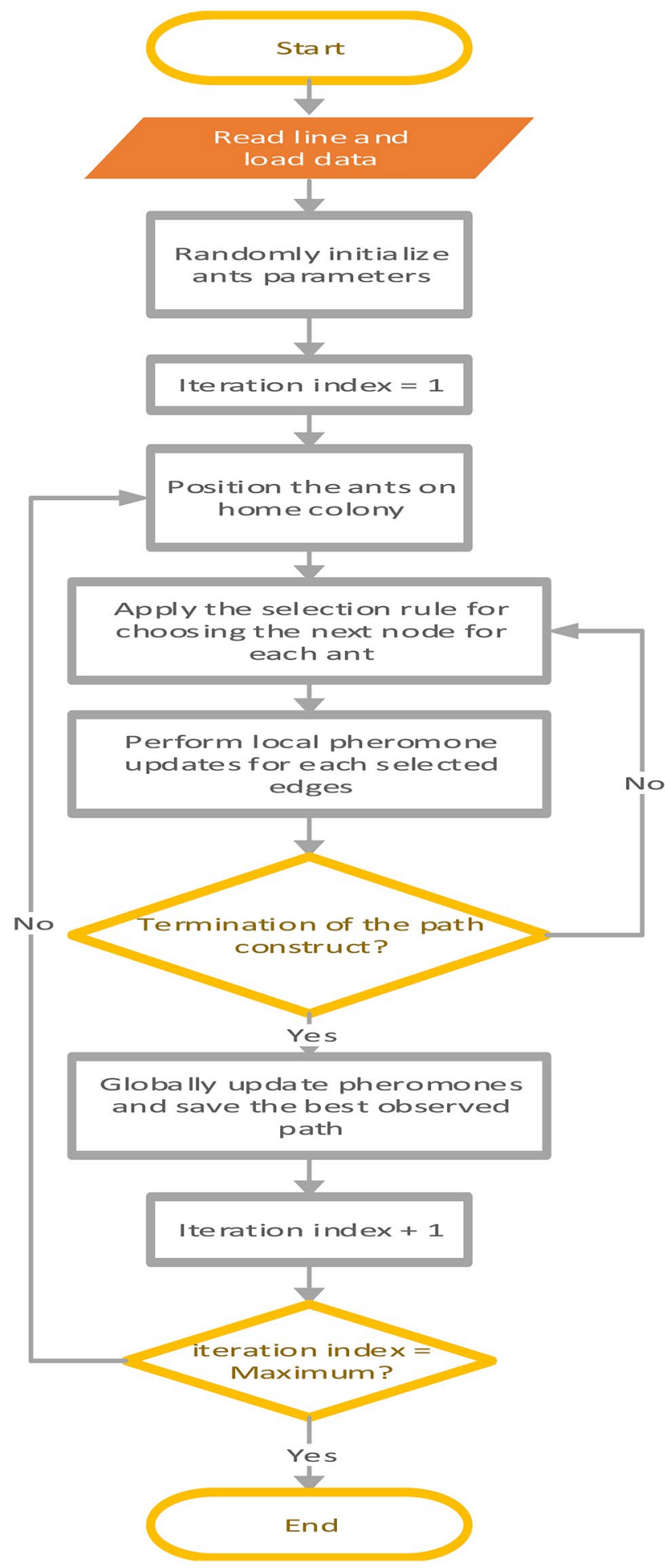

Fig. 1 Implementation flowchart of the ACO algorithm [33]

\section{Case study}

\subsection{Test system}

The proposed ACO algorithm was implemented in MATLAB R2016a and executed on an Intel ${ }^{\circledR}$ Pentium $^{\circledR}$ N3540 $2.16 \mathrm{GHz}$ personal computer, while the power flow algorithm for evaluating the fitness value of each solution generated by the ants was implemented using Matpower ${ }^{\otimes}$ library in MATLAB. It was tested on an IEEE 30-bus system. The total loads of the 30-bus system are 189.2 MW and 107.2 MVar, with its bus and branch parameters given in [34]. A schematic diagram of the test feeder is shown in Fig. 2.

The following assumptions were made in formulating the proposed method:

- Each bus within the system can take a maximum of one DG unit;

- The total DG penetration within the distribution system will not exceed $100 \%$ of the total load;

- The size of a single DG unit connected to a bus in the algorithm is allowed to can range from zero (no DG connected to the bus) to the total system load (100\% DG penetration with only 1 DG source);

- All the DGs have unlimited capability to supply real and reactive power according to the demand;

- All the buses, except bus 1 which is the reference bus, has the capacity for DG connection;

- Continuous values are assumed for the size of the DGs.

\subsection{Validation}

In order to validate the impact of results of the ACO algorithm, a model of the IEEE 30 bus system was developed using the Electrical Transient Analyzer Programme (ETAP) and load flow analysis of the system under the ACO derived optimal DG number, sites and sizes were carried out. The system was initially connected to the grid at bus 1 and the voltage profile at each of the 30 buses as well as the total system losses were recorded. Thereafter, 6 number generators were connected to the system, at first, the generators were connected at bus numbers $7,8,12,19$, 21 and 30 derived as the optimum sites for the DGs from the ACO analysis, the observed losses and system voltage profile are compared to the values obtained under grid power supply. To further revalidate the selection of the optimum site by the ACO algorithm, three additional case studies with the DGs sited at randomly selected buses with in the modelled system were evaluated. The IDs of the buses at which the DGs were sited under the various case studies are outlined in Table 1. The system voltage profile 


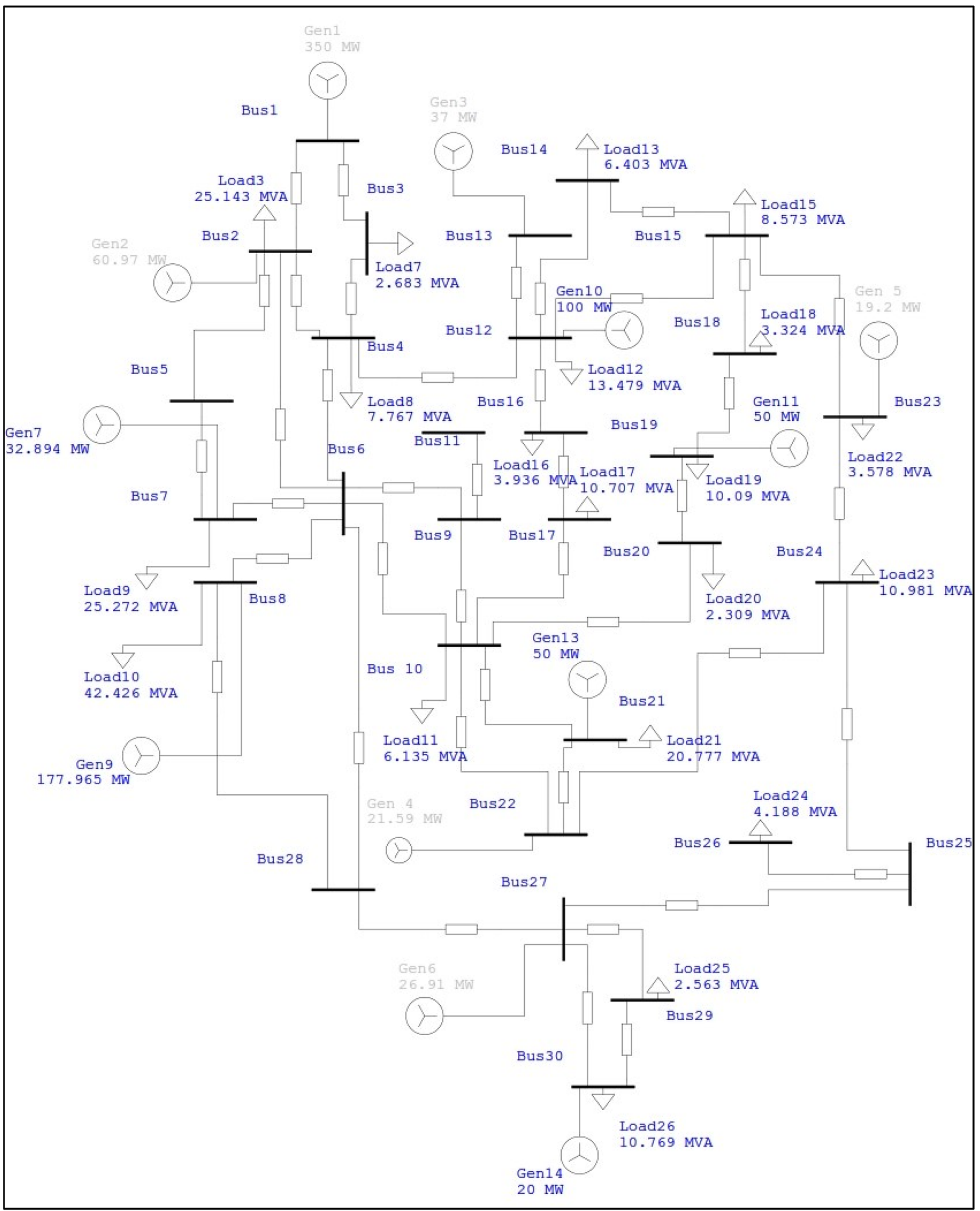

Fig. 2 ETAP Model of IEEE 30-Bus System 
Table 1 DG sites under different case studies for ETAP simulation

\begin{tabular}{ll}
\hline Case studies & DG sites (Bus ID) \\
\hline ACO optimized sites & $7,8,12,19,21$ and 30 \\
Case 1 & $1,2,13,19,22$ and 27 \\
Case 2 & $1,7,12,21,23$ and 27 \\
Case 3 & $1,2,12,23,26$ and 30 \\
\hline
\end{tabular}

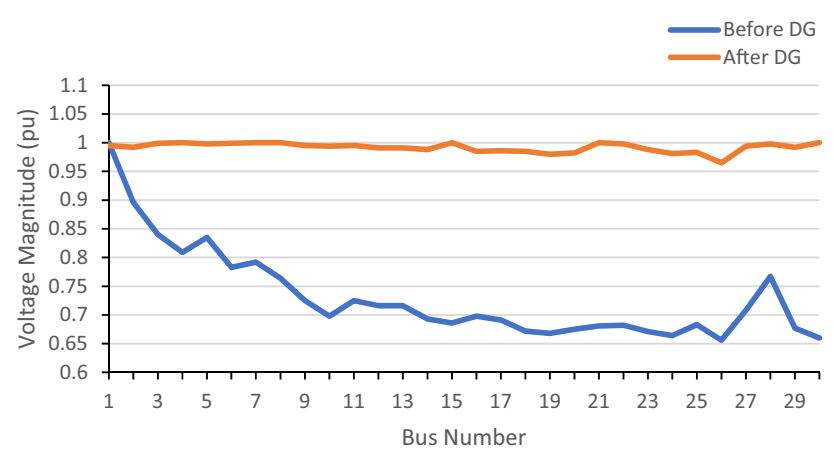

Fig. 3 Voltage magnitude at each bus before and after DG installation

and the total system losses were thereafter analyzed and the results presented.

\section{Results and discussion}

\subsection{ACO results}

The voltage magnitude across all the buses in the distribution system before and after ACO optimized DGs siting are presented in Fig. 3. It shows a significant improvement in the system voltage profile. In the base case, with the system only fed from the grid via Bus 1, there is a decline in the per unit (pu) voltage magnitude at the buses as we progress along the system from bus 1 to bus 30 . However, with the DGs sited at the optimum buses as derived using $\mathrm{ACO}$, there is a significant improvement in the voltage profile of the system with all the buses approaching the nominal voltage. Before DG siting, the least voltage magnitude across all the buses was obtained at bus 26 with a per unit voltage of 0.656 , however, after DG siting, this value increased by $47 \%$ to 0.965 per unit.

Similarly, as illustrated in Fig. 4 and Fig. 5, in the base case when the only power source of the network was situated at bus 1 , we observed significant real and reactive power losses from bus 1 to 10 , however, with the optimally

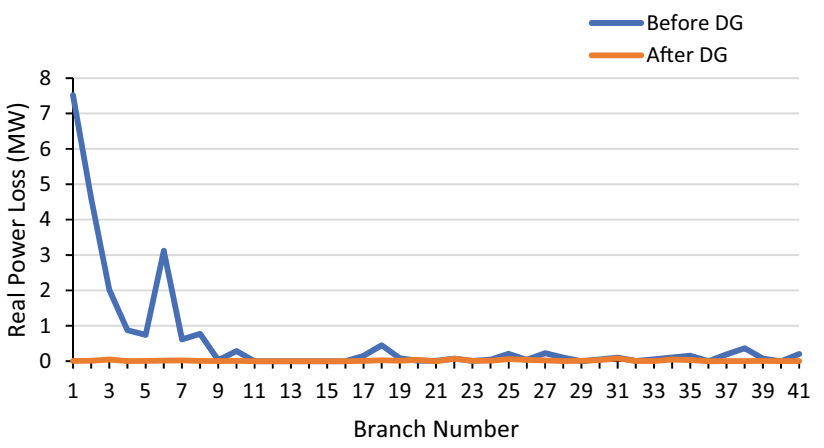

Fig. 4 Real power loss across the branches before and after DG installation

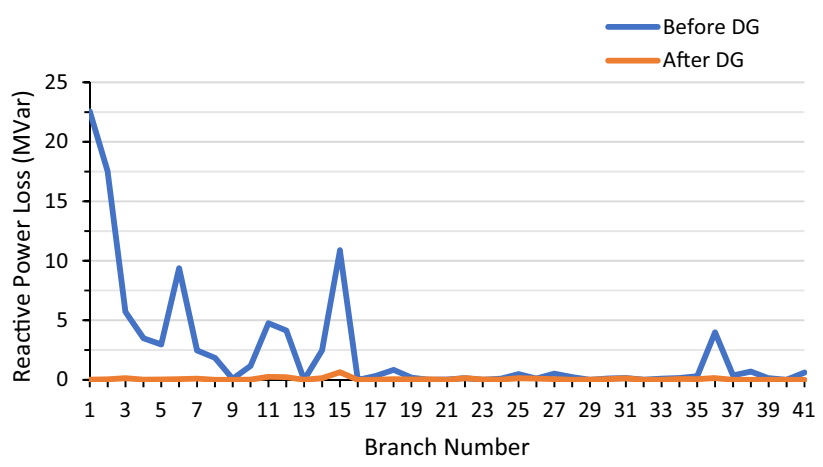

Fig. 5 Reactive power loss across the branches before and after DG installation

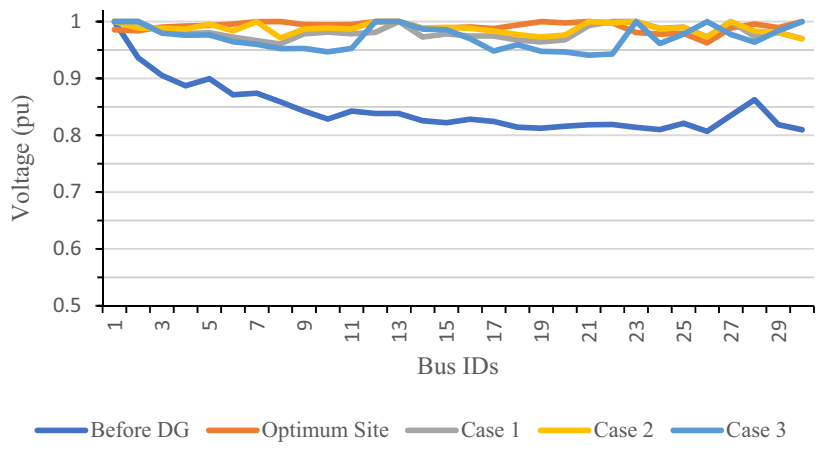

Fig. 6 ETAP derived voltage profile across all the system buses

sized and sited DGs, the losses reduced drastically across all the branches, with values approaching zero as close as possible.

\subsection{Comparison of ACO with ETAP}

The analysis of the distribution system voltage profile as derived from ETAP under the various distributed generation arrangement are illustrated in Fig. 6 . The ACO results 
as presented in Fig. 3 with the obtained results from ETAP shown in Fig. 6 for optimized site plot are in good correlation with an average difference of $0.52 \%$. It is also shown in Fig. 6 that there is a significant improvement in the voltage profile when the system is fed by DGs compared to when it is only fed from the grid. Also, while the voltage at some of the buses under the other three case studies are better than when the DGs are sited at the ACO optimized sites, the best overall voltage profile is obtained at the ACO optimized sites.

Table 2 presents the summary of results of the ACO optimized sites with the DG sites of randomly selected buses simulated in ETAP. It revealed that the total real and reactive power losses within the system reduced by $92 \%$ and $97 \%$, respectively when the distribution system is fed by six DGs sited at the ACO optimized locations relative to the values under grid power supply. Also, the highest reduction in losses was obtained with the DGs sited at the ACO derived sites as against when they are sited at other locations within the distribution system, as obtained in Case 1, 2 and 3. This is also illustrated in Fig. 7 which shows a significant reduction in the total real and reactive power losses across the system when DGs are sited at various locations within the system under the four case studies, however, the least losses are obtained when the DGs are sited at the ACO derived optimum buses.

The results showed that the ACO based approach presented in this paper was able to achieve a $92 \%$ reduction in real power loss and a $97 \%$ reduction in reactive power loss within the distribution system. Compared to other reviewed literatures on the subject, this method resulted in the highest reduction in real and reactive power losses. A $67.01 \%$ reduction in losses was derived using Differential evolution technique [35]. Using a hybrid of GA and an analytical solution, a reduction in system losses of $83.74 \%$ was derived in [36]. Using closed-form analytical expressions, a maximum reduction in real power losses of $95 \%$ and $94 \%$ reduction in the reactive power losses, which is comparable with the result obtained in this study with

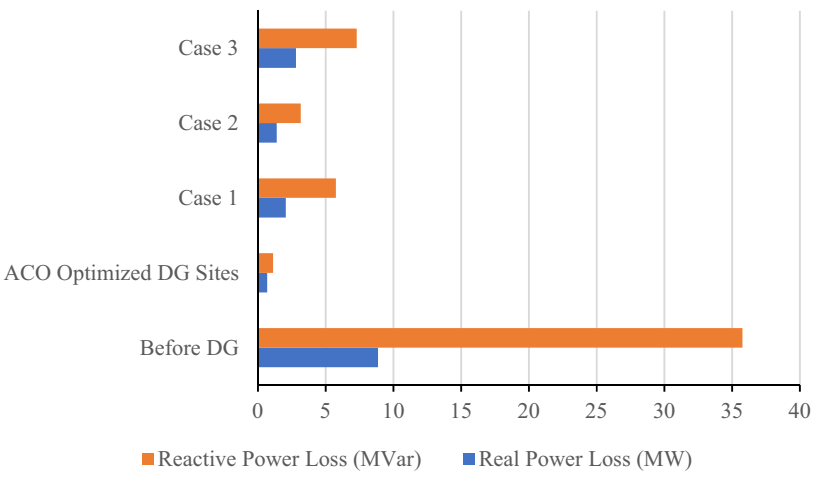

Fig. 7 Total real and reactive power losses under different case studies

the ACO method presented achieving this with a much smaller search space [12]. The superior performance of the method could be attributed to the fact that the algorithm is not excessively constrained with the optimum combination of DG power factors, the number, the capacity and the location of DGs heuristically derived by the algorithm coupled with the superior capacity of ACO to converge as the global minima compared with other metaheuristic algorithms.

\section{Conclusion}

The proper placement and sizing of DGs in a power distribution system plays a significant role in reducing the total real and reactive losses as well as improves the voltage profile within the system. In this paper, an optimization method for determining the optimal sites and capacities of distributed generation resources in a power distribution network using Ant Colony Optimization was presented. The problem consists of two types of variable, the DG placement problem which is discrete in nature and generators' sizing which is of a continuous variable type. The
Table 2 Voltage profile and total system losses

\begin{tabular}{llllll}
\hline & Before DG & $\begin{array}{l}\text { ACO Opti- } \\
\text { mized Sites }\end{array}$ & Case 1 & Case 2 & Case 3 \\
\hline Average bus voltages & 0.8460 & 0.9914 & 0.9809 & 0.9878 & 0.9718 \\
\% Increase in average bus voltages & & $17.19 \%$ & $15.95 \%$ & $16.76 \%$ & $14.87 \%$ \\
Standard deviation of bus voltages & 0.0429 & 0.0083 & 0.0118 & 0.0093 & 0.0201 \\
Min bus voltage & 0.8069 & 0.9626 & 0.9607 & 0.9698 & 0.9409 \\
Max bus voltage & 1 & 1 & 1 & 1 & 1 \\
Total real power loss (MW) & 8.862 & 0.675 & 2.057 & 1.383 & 2.799 \\
Total reactive power loss (MVar) & 35.756 & 1.111 & 5.746 & 3.149 & 7.291 \\
\% Reduction in real power loss & & $-92 \%$ & $-77 \%$ & $-84 \%$ & $-68 \%$ \\
\% Reduction in reactive power loss & & $-97 \%$ & $-84 \%$ & $-91 \%$ & $-80 \%$ \\
\hline
\end{tabular}


results obtained showed that the ACO based approach resulted in a significant reduction in the total real and reactive power losses as well as improvement in the voltage profile of the power distribution network as a result of the DGs. The impact of the optimally sized and sited DGs was also significantly higher than the figures achieved in most past research work on the same subject.

In the future, this research work will be extended by considering and modelling the different types of renewable energy sources in formulating the problem rather than using a generic DG source with the capacity to generate any amount of real power and supply or sink any amount of reactive power as presented in this work. Furthermore, more work still needs to be done to solve the planning and dispatch problem associated with a high penetration of renewable energy DGs in a power distribution system due to the variable nature of renewable energy sources.

\section{Compliance with ethical standards}

Conflict of interest The authors declare that they have no conflict of interest.

Open Access This article is licensed under a Creative Commons Attribution 4.0 International License, which permits use, sharing, adaptation, distribution and reproduction in any medium or format, as long as you give appropriate credit to the original author(s) and the source, provide a link to the Creative Commons licence, and indicate if changes were made. The images or other third party material in this article are included in the article's Creative Commons licence, unless indicated otherwise in a credit line to the material. If material is not included in the article's Creative Commons licence and your intended use is not permitted by statutory regulation or exceeds the permitted use, you will need to obtain permission directly from the copyright holder. To view a copy of this licence, visit http://creativecommons .org/licenses/by/4.0/.

\section{References}

1. Chowdhury BH, Tseng C-L (2007) Distributed energy resources: issues and challenges. J Energy Eng 2007:109-110. https://doi. org/10.1061/(ASCE)0733-9402133:3(109)

2. Galgali VS, Ramachandran M, Vaidya GA (2019) Multi-objective optimal sizing of distributed generation by application of Taguchi desirability function analysis. SN Appl Sci 1:1-14. https://doi. org/10.1007/s42452-019-0738-3

3. Kalkhambkar V, Rawat B, Kumar R, Bhakar R (2017) Optimal allocation of renewable energy sources for energy loss minimization. J Electr Syst 113:115-130

4. Caamaño-Martín E, Laukamp $H$, Jantsch $M$, Erge $T$, Thornycroft J, De Moor H, Cobben S, Suna D, Gaiddon B (2008) Interaction between photovoltaic distributed generation and electricity networks. Prog Photovoltaics Res Appl 16:629-643. https://doi. org/10.1002/pip.845

5. Miller N, Ye Z (2003) Report on Distributed Generation Penetration Study. United States, 2003. https://doi.org/10.2172/15004 478
6. Ajan, A., John, N (2015) Performance evaluation of on-grid and off-grid solar photovoltaic systems. IJIREEICE, https://doi. org/10.17148/ijireeice.2015.3205

7. Kazemi A, Sadeghi M (2009) Sitting and sizing of distributed generation for loss reduction. In proceedings of the asia-pacific power and energy engineering conference, APPEEC pp. 1-6

8. Ghosh N, Sharma S, Bhattacharjee S (2012) A load flow based approach for optimum allocation of distributed generation units in the distribution network for voltage improvement and loss minimization. Int J Comput Appl 50:15-22. https://doi. org/10.5120/7847-1075

9. Arjun YM, Suresh BR (2013) Impact of distributed generation on three feeder radial distribution system. Int J Eng Res Appl 3:983-988

10. Ramesh L, Chowdhury SP, Chowdhury S, Natarajan AA, Gaunt CT (2009) Minimization of power loss in distribution networks by different techniques. Int J Electr Electron Eng 2:521-527

11. Mahmoud K, Lehtonen M (2020) Direct approach for optimal allocation of multiple capacitors in distribution systems using novel analytical closed-form expressions. Electr Eng. https://doi. org/10.1007/s00202-020-01073-9

12. Mahmoud K, Lehtonen M (2019) Simultaneous allocation of multi-type distributed generations and capacitors using generic analytical expressions. IEEE Access 7:182701-182710. https:// doi.org/10.1109/ACCESS.2019.2960152

13. Mahmoud K, Ahmed A (2015) Power loss minimization in distribution systems using multiple distributed generations. IEEJ Trans Electr Electron Eng 10:521-526. https://doi.org/10.1002/ tee. 22115

14. Petinrin JO, Shaaban M (2018) Multiperiod coordination of local voltage controllers and energy storage for voltage regulation in distribution feeder-connected renewable energy sources. Iran J Sci Technol Trans Electr Eng. https://doi.org/10.1007/s4099 8-018-0092-2

15. Fawzi TH, El-Sobki SM, Abdel-Halim MA (1983) New approach for the application of shunt capacitors to the primary distribution feeders. IEEE Trans Power Appar Syst 102:10-13s

16. Resener M, Haffner S, Pereira LA, Pardalos PM, Ramos MJS (2019) A comprehensive MILP model for the expansion planning of power distribution systems-Part I: problem formulation. Electr Power Syst Res 170:378-384. https://doi.org/10.1016/j. epsr.2019.01.040

17. Janga Reddy M, Nagesh Kumar D (2020) Evolutionary algorithms, swarm intelligence methods, and their applications in water resources engineering: a state-of-the-art review. $\mathrm{H} 2 \mathrm{Open}$ J 3 135-188. https://doi.org/10.2166/h2oj.2020.128

18. Abdmouleh Z, Gastli A, Ben-Brahim L, Haouari M, Al-Emadi NA (2017) Review of optimization techniques applied for the integration of distributed generation from renewable energy sources. Renew Energy 113:266-280. https://doi.org/10.1016/j. renene.2017.05.087

19. El-Khattam W, Bhattacharya K, Hegazy Y, Salama MMA (2004) Optimal investment planning for distributed generation in a competitive electricity market. IEEE Trans Power Syst 19:16741684. https://doi.org/10.1109/TPWRS.2004.831699

20. Kuri B, Redfern MA, Li F (2004) Optimisation of rating and positioning of dispersed generation with minimum network disruption. In: Proceedings of the 2004 IEEE Power Engineering Society General Meeting 2:2074-2078

21. Golshan MEH, Arefifar SA (2006) Distributed generation, reactive sources and network-configuration planning for power and energy-loss reduction. IEE Proc Gener Transm Distrib 153:127136. https://doi.org/10.1049/ip-gtd

22. Gandomkar M, Vakilian M, Ehsan M (2005) A combination of genetic algorithm and simulated annealing for optimal DG 
allocation in distribution networks. Proc Can Conf Electrical Comput Eng 2005:645-648

23. Kalkhambkar V, Kumar R, Bhakar R (2016) Joint optimal allocation methodology for renewable distributed generation and energy storage for economic benefits. IET Renew Power Gener 10:1422-1429. https://doi.org/10.1049/iet-rpg.2016.0014

24. Kalkhambkar V, Kumar R, Bhakar R (2016) Joint optimal allocation of battery storage and hybrid renewable distributed generation. In: Proceedings of IEEE 6th International Conference on Power Systems (ICPS), New Delhi, 2016, pp 1-6. https://doi. org/10.1109/ICPES.2016.7584058

25. Kalkhambkar V, Kumar R, Bhakar R (2017) Joint optimal sizing and placement of renewable distributed generation and energy storage for energy loss minimization. In: Proceedings of 4th international conference on advanced computing and communication systems (ICACCS), Coimbatore, 2017, pp 1-9. https://doi.org/10.1109/ICACCS.2017.8014596

26. Celli G, Ghiani E, Mocci S, Pilos F (2003) A multi-objective formulation for the optimal sizing and siting of Embedded Generation in distribution networks. In: proceedings of the 2003 IEEE Bologna PowerTech - conference proceedings 1, pp 67-75

27. Gopiya NS, Khatod DK, Sharma MP (2012) Optimal allocation of distributed generation in distribution system for loss reduction. IACSIT Coimbatore Conf 28:42-46

28. Gupta A, Srivastava S (2020) Comparative analysis of ant colony and particle swarm optimization algorithms for distance optimization. Procedia Comput Sci 173:245-253. https://doi. org/10.1016/j.procs.2020.06.029

29. Mukhairez HHA, Maghari AYA (2015) Performance comparison of simulated annealing, GA and ACO applied to TSP. Int J Intell Comput Res 6:647-654
30. Farhat IA (2013) Ant colony optimization for optimal distributed generation in distribution systems. World Acad Sci Eng Technol 7:461-465

31. Dorigo M, Gambardella LM (1997) Ant colony system: a cooperative learning approach to the traveling salesman problem. IEEE Trans Evol Comput 1:53-66. https://doi.org/10.1109/4235.585892

32. Yang X-S (2018) Mathematical analysis of nature-inspired algorithms. In:Yang X-S (ed) Nature-Inspired Algorithms and Applied Optimization: Studies in Computational Intelligence. Springer International Publishing AG, Cham, pp 1-25

33. Hu XM, Zhang J, Chung HSH, Li Y, Liu O (2010) SamACO: variable sampling ant colony optimization algorithm for continuous optimization. . IEEE Trans Syst Man Cybern Part B Cybern 40:1555-1566. https://doi.org/10.1109/TSMCB.2010.2043094

34. Kashem MA, Ganapathy V, Jasmon GB, Buhari MI (2002) A novel method for loss minimization in distribution networks. In: Proceedings of International Conference on Electric Utility Deregulation and Restructuring and Power Technologies. Proceedings (Cat. No.00EX382), London, UK, 2000, pp 251-256. https://doi. org/10.1109/DRPT.2000.855672

35. Hussain I, Roy AK (2012) Optimal size and location of distributed generations using differential evolution (DE). Proc - 2012 2nd Natl Conf Comput Intell Signal Process CISP 2012:57-61. https ://doi.org/10.1109/NCCISP.2012.6189708

36. Borges CLT, Falcão DM (2006) Optimal distributed generation allocation for reliability, losses, and voltage improvement. Int J Electr Power Energy Syst 28:413-420. https://doi.org/10.1016/j. ijepes.2006.02.003

Publisher's Note Springer Nature remains neutral with regard to jurisdictional claims in published maps and institutional affiliations. 